\title{
IDENTITAS VISUAL DAN PENERAPANNYA PADA SIGNAGE UNTUK KAWASAN WISATA EDUKASI
}

\author{
Ahmad Zakiyy Maymun, Wirania Swasty \\ (Email: zakiyyahmad@gmail.com) \\ Program Studi Desain Komunikasi Visual \\ Fakultas Industri Kreatif \\ Universitas Telkom Bandung \\ Jl. Telekomunikasi No. 1, Bandung, Indonesia
}

\begin{abstract}
ABSTRAK
Objek wisata merupakan suatu tempat yang menjadi sasaran untuk berekreasi di akhir pekan ataupun hari libur. Salah satu objek wisata di daerah Bandung adalah Kampung Batu Malakasari sebagai kasus studi penelitian ini. Mengusung tema 'Wisata Edukasi', diharapkan pengunjung dapat menikmati keindahan alam sekaligus mendapatkan ilmu pengetahuan. Masalah yang terjadi adalah pengunjung tidak bisa mengenali identitas visual dari objek wisata tersebut karena tidak selaras dengan tema yang diangkat. Selain itu, kurangnya signage yang memberikan informasi berupa tulisan maupun sajian visual mengenai petunjuk arah ke wahana, peta lokasi, larangan, hingga peringatan yang membuat pengunjung kebingungan dan seringkali tersesat menuju kawasan wisata. Oleh karena itu, identitas visual dan penerapannya pada signage dianggap perlu. Metode pengumpulan data yang digunakan ialah observasi, wawancara dan kuesioner dengan menggunakan analisis matriks sebagai metode analisis. Tujuan dari hasil perancangan ini diharap dapat menciptakan identitas visual yang kuat untuk menunjukkan wisata edukasi serta signage yang informative supaya dapat meningkatkan daya tarik visual yang melekat di benak pengunjung.
\end{abstract}

Kata kunci: identitas visual; signage; wisata edukasi

\begin{abstract}
Tourist attraction is a destination place for recreation on weekends or holidays. One of tourist attractions in Bandung is Kampung Batu Malaksari as a case of this study. With the theme 'Education Tourism', visitors are expected to enjoy the beauty of nature as well as get the knowledge. However, visitors cannot recognize the visual identity of the tourist attraction because it is not aligned with the theme. Moreover, the lack of signage that provides information in text and visual presentation of directions to the place, directory map, prohibitory, and warning that makes visitors confused and often lost to the tourist area. Therefore, the visual identity and its application to signage is considered necessary. Data collection methods used were observations, interviews and questionnaires using matrix analysis as a method of analysis. The purpose of this study is expected to create a strong visual identity that shows educational tourism as well as informative signage. This case study is expected to improve the visual appeal inherent in the visitor's mind.
\end{abstract}

Keywords: educational tourism; signage; visual identity 


\section{PENDAHULUAN}

Kampung Batu Malakasari merupakan destinasi wisata alam yang mengusung tema "Wisata Edukasi" dilengkapi fasilitas dan wahana untuk dapat melatih ketangkasan, kecerdasan, dan kemandirian pada pengunjung, khususnya keluarga dan anak-anak. Kampung Batu Malakasari diharapkan dapat menjadi ikon wisata yang tidak hanya dikenal oleh masyarakat sekitar tetapi juga oleh masyarakat luas. Akan tetapi, pengelola kurang menyadari pentingnya sebuah identitas visual seperti logo sebagai penguat citra merek dari suatu perusahaan. Kurangnya kesadaran diakibatkan karena kurangnya pemahaman mengenai pembuatan sebuah logo yang sesuai dengan standar dari pembuatan logo yang harus sesuai dengan visi, misi, serta konsep yang dipakai oleh tempat wisata tersebut sebagai penyampaian citra perusahaan (Anggraeni dan Kirana, 2014).

Selain identitas visual yang belum sesuai dengan standar pembuatan untuk identitas logo, Kampung Batu Malakasari juga belum mempunyai signage yang memadai serta tidak sesuai dengan standarisasi. Dapat dilihat dari penggunaan huruf, warna, penempatan signage yang belum memenuhi tiga prinsip dasar pembuatan signage yaitu visibility, reability, dan legability serta kurangnya media untuk menginformasikan kepada wisatawan mengenai fasilitas dan wahana yang ada (Tinarbuko, 2012). Tidak hanya logo sebagai identitas, signage pun bisa menjadi sebagai salah satu penunjang identitas dari objek wisata (Christianna, 2016). Oleh karena itu, Kampung Batu Malakasari perlu membuat identitas visual dan penerapannya pada signage yang sesuai dengan standar agar dapat memperkuat identitas visual dalam menumbuhkan citra Kampung Batu Malakasari.

Latar belakang masalah adalah kurangnya identitas visual serta penerapan signage pada kawasan Kampung Batu Malakasari untuk menambah awareness terhadap pengunjung sebagai tempat wisata yang edukatif. Berdasarkan latar belakang tersebut, dilakukan studi mengenai pembentukkan citra Kampung Batu Malakasari dengan identitas visual untuk menggambarkan wisata edukasi dan menerapkan signage yang sesuai dengan standar. Rumusan masalah dalam perancangan ini adalah bagaimana memperkuat perancangan identitas dan penerapan pada signage untuk sebuah kawasan wisata edukasi? 


\section{METODE PENELITIAN}

Penelitian ini menggunakan studi kasus dengan pendekatan kualitatif dan kuantitatif. Studi pustaka melalui jurnal-jurnal yang berkaitan dengan perancangan identitas visual dan signage. Kemudian observasi dilakukan dengan mengunjungi langsung ke tempat yang dijadikan objek penelitian yaitu Kampung Batu Malakasari yang berada di Bandung Selatan serta mengambil gambar untuk dijadikan dokumentasi.

Data primer lainnya dengan melakukan wawancara kepada pihak-pihak yang bersangkutan dengan mengajukan pertanyaan secara langsung untuk memperoleh data yang diperlukan antara lain pihak pemilik lokasi, pegawai sekitar, dan pengunjung yang ada di tempat tersebut. Selain itu, kuesioner disebar dengan memberikan selembar kertas berupa pertanyaan-pertanyaan singkat yang sesuai dengan topik penelitian kepada wisatawan yang ada di lokasi wisata serta menyebarkan secara online menggunakan Google Forms kepada wisatawan yang sudah pernah mengunjungi tempat wisata tersebut, agar didapat data yang valid.

\section{Kajian Teori}

Desain komunikasi visual adalah ilmu yang mempelajari konsep komunikasi dan ungkapan kreatif yang diaplikasikan dalam berbagai media komunikasi visual dengan mengelola elemen desain grafis terdiri dari gambar atau ilustrasi, huruf, warna, komposisi dan layout di dalam buku prinsip-prinsip desain komunikasi visual. Menurut Sutanto (2005:15-16), sebuah karya atau desain berhubungan dengan penampilan dari gambar yang dapat dirasakan oleh orang banyak dengan pikiran maupun perasaannya. Sebuah gambar mengandung pengertian atau makna, karakter serta suasana, yang mampu dipahami oleh khalayak umum atau terbatas.

Dalam desain komunikasi visual tentunya sangat berhubungan dengan identitas visual (Heskett, 2002:125) yakni identitas ini memiliki bentuk berupa simplifikasi dari konsep dan ide-ide kompleks yang dimiliki tiap orang atau perusahaan. Kemudian strategi komunikasi menurut Shimp (2003:357) adalah menginformasikan (informing), mempengaruhi serta membujuk (persuading) dan mengingatkan (reminding) wisatawan tentang tempat wisata dan bauran wisatanya. Berdasarkan Oxford Dictionaries, logo adalah sebuah simbol atau desain kecil lainnya yang diadopsi oleh sebuah organisasi untuk mengidentifikasi produk, 
seragam, maupun kendaraannya. Menurut Rustan (2013), terdapat empat fungsi logo yaitu: identitas diri, tanda kepemilikan, tanda jaminan kualitas, dan mencegah peniruan.

Signage merupakan suatu bidang grafis yang mengkomunikasikan infomasi dalam membentuk sebuah lingkungan. Informasi yang dikomunikasikan berupa komunikasi grafis. Aktivitas dari Environmental Graphic Design (EGD) melibatkan pengembangan sistematis, sistem informasi kohesif dan sistem komunikasi visual grafis pada sebuah situs dengan lingkungan yang dibangun (Calori, 2007:4). EGD dbagi menjadi tiga bagian yaitu: signage, wayfinding, dan placemaking.

Hardware System merupakan suatu program sign tiga dimensi yang dapat ditekan, disentuh, dilihat, dan berbentuk fisik. Hardware system terdiri dari bentuk, struktur, bahan, pemasangan, dan sebagainya (Calori, 2007). Sign informasi dapat mengkomunikasikan sebuah gambar walaupun tidak terdapat tulisan. Sedangkan pictorial, dapat berupa simbol yaitu sebuah gambar dapat mempresentasikan sesuatu atau sebuah konsep dan diagram, contohnya adalah peta (Calori, 2007).

A.J. Burkart dalam Damanik dan Weber (2006) mengemukakan pariwisata dapat disebut dengan perpindahan seseorang atau keluarga yang melakukan perjalanan ke berbagai tempat dalam waktu yang singkat untuk melakukan suatu aktivitas yang berbeda dari hal yang biasanya. Menurut Mathieson \& Wall dalam Pitana dan Gayatri (2005), pariwisata merupakan kegiatan perpindahan untuk sementara waktu ke sebuah destinasi yang jauh dari tempat mereka tinggal dan melakukan kegiatan yang berbeda dari biasanya dengan menyiapkan berbagai fasilitas untuk memenuhi kebutuhan liburan. Lalu menurut Soetomo (1994), yang dilandaskan pada ketentuan WATA (World Association of Travel Agent), wisata merupakan suatu perjalanan yang dilakukan dengan berkeliling ke suatu tempat dengan melihat-lihat lingkungan sekitar yang berbeda.

Pengertian edukasi menurut Suroso dan Rendra (2004) adalah upaya seseorang terhadap sebuah objek untuk mengubah cara mengelola dan mengembangkan pengetahuan menuju berbagai cara yang diinginkan subjek. Edukasi berasal dari kata latin yaitu educare yang artinya memunculkan, membawa, dan melahirkan tetapi di dalam pengertian secara luas edukasi yaitu sebuah karakter yang memiliki pengalaman dengan efek formatif, pikiran, atau kemampuan fisik dalam individu. Edukasi serta pendidikan mempunyai arti yang 
berbeda, pendidikan adalah media perubahan dari sikap dan tata laku seseorang di dalam mengubah untuk mendewasakan manusia yang melalui pengajaran, proses, latihan dan cara mendidik (Kamus Besar Bahasa Indonesia, 1990).

\section{PEMBAHASAN}

Kampung Batu Malakasari berada di Jl. Raya Banjaran (Rencong) Desa Malakasari Bandung dengan mengusung konsep wisata edukasi outdoor. Kampung Batu memiliki ciri khas dengan gaya alam bebatuan, danau, dan pepohonan. Selain mempunyai ciri khas tersendiri, kawasan wisata ini memiliki banyak wahana serta fasilitas yang ada di dalamnya. Dibandingkan dengan pesaingnya yaitu Kampung Gajah dan De'Ranch, Kampung Batu Malakasari tertinggal dalam hal identitas visual dan signage.

Berdasarkan hasil wawancara yang dilakukan dengan pengelola Kampung Batu Malakasari, pengunjung datang ke tempat wisata ini mendapatkan kepuasan serta pembelajaran dari wahana yang ada. Keunikan yang ditonjolkan adalah bukit batu serta rusa totol. Identitas yang ditonjolkan belum terlihat seperti keunikan dari Kampung Batu Malakasari sehingga butuh redesain agar lebih simple dan mudah diingat oleh pengunjung. Signage yang ada saat ini juga kurang diperhatikan dan tidak sesuai dengan identitas visual yang ada. Terkadang ada pengunjung yang meresa kebingungan karena signage yang ada terlalu kecil dan jarangnya petunjuk arah. Peta yang ada saat ini pun hanya dibuat seadanya saja. Karena itu dibutuhkan perbaikan agar dapat memperindah lingkungan di kawasan wisata Kampung Batu Malakasari.

Sedangkan wawancara yang dilakukan dengan desainer signage Endra Waskito dan Andy Rahmat, terungkap bahwa signage yang sesuai dengan standar harus memenuhi beberapa prinsip di antaranya harus mudah dimengerti, informatif, bentuk, ukuran font serta penempatan harus sesuai agar mudah dilihat. Sebagai desainer signage, terlebih dahulu harus mengerti dasar ilmu serta teknisnya seperti material, penempatan lokasi, ukuran dan desainnya agar desain yang dibuat sesuai dengan identitas serta ciri khas tempat tersebut serta pesan dapat tersampaikan kepada penerima, dalam hal ini pengunjung kawasan wisata tersebut.

Berdasarkan hasil kuesioner yang disebar kepada pengunjung Kampung Batu Malakasari berusia 5-45 tahun, terungkap bahwa identitas visual dan signage yang ada saat ini belum 
memenuhi standar dari pembuatannya yakni logo tidak menarik dan tidak mudah untuk dilihat. Demikian pula signage tidak menarik perhatian pengunjung dan penempatan yang sulit dilihat, kurang informatif, font yang tidak terlihat serta desain yang kurang menarik. Responden lebih menyukai desain yang menggunakan gambar dan tulisan baik pada logo maupun signage.

Tabel 1. Analisis Signage

\begin{tabular}{|c|c|c|c|}
\hline & $\begin{array}{l}\text { Kampung Batu } \\
\text { Malakasari }\end{array}$ & Kampung Gajah & De'Ranch \\
\hline Gambar & 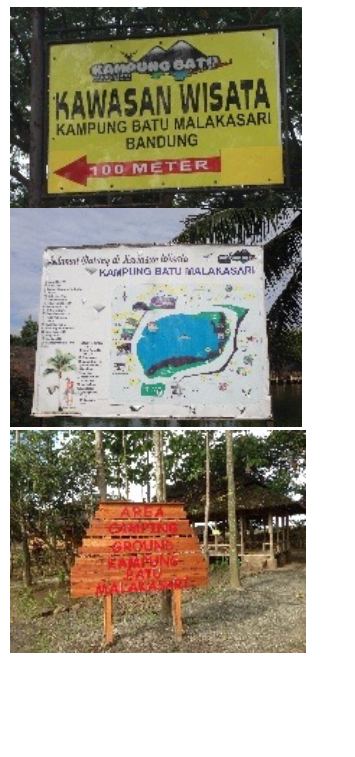 & bi & 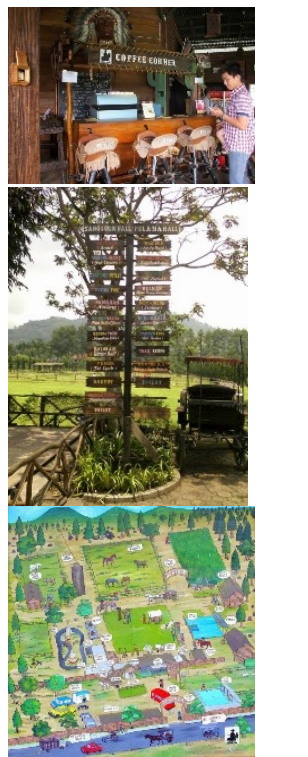 \\
\hline \multirow[t]{3}{*}{ Visibility } & \multicolumn{3}{|c|}{ Penggunaan Warna } \\
\hline & $\begin{array}{l}\text { Warna pada sign tertentu } \\
\text { sebagian sudah sesuai } \\
\text { dengan code warna } \\
\text { signage. Sign untuk } \\
\text { memasuki wahana serta } \\
\text { pada peta penggunaan } \\
\text { warnanya belum sesuai } \\
\text { dan mengganggu } \\
\text { keterbacaan pengunjung. }\end{array}$ & $\begin{array}{l}\text { Warna pada sign } \\
\text { menarik serta } \\
\text { konsisten pada } \\
\text { beberapa sign yang } \\
\text { ada, sedangkan yang } \\
\text { lainnya menggunakan } \\
\text { warna standar dari } \\
\text { signage }\end{array}$ & $\begin{array}{l}\text { Warna dari signage } \\
\text { mempertahankan } \\
\text { warna dari kayu } \\
\text { sebagaimana bahan } \\
\text { dasarnya, hanya } \\
\text { memainkan warna } \\
\text { pada fontnya saja. Ada } \\
\text { sebagian font yang } \\
\text { tidak terbaca karena } \\
\text { warnanya yang tidak } \\
\text { kontras dengan } \\
\text { backgroundnya. }\end{array}$ \\
\hline & \multicolumn{3}{|c|}{ Penempatan Signage } \\
\hline
\end{tabular}




\begin{tabular}{|c|c|c|c|}
\hline & $\begin{array}{l}\text { Penempatan yang kurang } \\
\text { tepat dan tidak sesuai } \\
\text { dengan penempatan } \\
\text { yang sudah ditentukan } \\
\text { oleh standar signage. } \\
\text { Banyak signage yang } \\
\text { tidak terlihat atau } \\
\text { tertutup oleh sesuatu } \\
\text { yang ada di lokasi serta } \\
\text { penempatan yang tidak } \\
\text { strategis untuk dilihat } \\
\text { oleh pengunjung. Banyak } \\
\text { juga signage yang hanya } \\
\text { ditempelkan di } \\
\text { pepohonan } \\
\text { menggunakan paku. }\end{array}$ & $\begin{array}{l}\text { Beberapa sign sudah } \\
\text { sesuai pada } \\
\text { penempatannya yang } \\
\text { dapat membuat } \\
\text { pengunjung bisa } \\
\text { leluasa melihatnya, } \\
\text { tetapi ada sebagian } \\
\text { sign yang } \\
\text { penempatannya } \\
\text { kurang tepat sehingga } \\
\text { tertutup oleh pohon. }\end{array}$ & $\begin{array}{l}\text { Beberapa sign tidak } \\
\text { sesuai penempatannya } \\
\text { dan kontrasnya kurang } \\
\text { jelas terkadang } \\
\text { backlight jadi tidak } \\
\text { terlihat tulisannya. Sign } \\
\text { yang lainnya sudah } \\
\text { sesuai penempatan } \\
\text { dan memiliki } \\
\text { keterlihatan yang baik } \\
\text { oleh pengunjung. }\end{array}$ \\
\hline & \multicolumn{3}{|c|}{ Material Signage } \\
\hline & $\begin{array}{l}\text { Material yang digunakan } \\
\text { tidak konsisten. Beberapa } \\
\text { signage menggunakan } \\
\text { banner print, kayu, serta } \\
\text { alumunium. }\end{array}$ & $\begin{array}{l}\text { Bahan yang digunakan } \\
\text { untuk hampir semua } \\
\text { signage menggunakan } \\
\text { bahan fiber hanya } \\
\text { beberapa saja yang } \\
\text { menggunakan banner } \\
\text { dan alumunium. }\end{array}$ & $\begin{array}{l}\text { Bahan yang digunakan } \\
\text { hampir semuanya } \\
\text { memakai bahan kayu, } \\
\text { hanya beberapa saja } \\
\text { yang menggunakan } \\
\text { alumunium. }\end{array}$ \\
\hline & \multicolumn{3}{|c|}{ Bentuk Signage } \\
\hline & $\begin{array}{l}\text { Sebagian sign bentuknya } \\
\text { unik dan yang lainya } \\
\text { standar bentuk persegi } \\
\text { panjang. }\end{array}$ & $\begin{array}{l}\text { Bentuk signage sudah } \\
\text { konsisten menerapkan } \\
\text { logo di atas } \\
\text { signagenya dan } \\
\text { sebagian signage } \\
\text { hanya standar saja } \\
\text { tidak semuanya sama } \\
\text { rata. }\end{array}$ & $\begin{array}{l}\text { Bentuk signage sudah } \\
\text { konsisten } \\
\text { mempertahankan dari } \\
\text { tema dan objek } \\
\text { kayunya. }\end{array}$ \\
\hline Readibility & $\begin{array}{l}\text { Informasi yang } \\
\text { ditunjukkan oleh signage } \\
\text { yang sudah ada belum } \\
\text { efektif. Penempatan peta } \\
\text { yang tinggi dari } \\
\text { jangkauan mata serta } \\
\text { grafis yang tidak menarik } \\
\text { dan kondisi yang tidak } \\
\text { terawat membuat } \\
\text { beberapa informasi tidak } \\
\text { berfungsi. }\end{array}$ & $\begin{array}{l}\text { Informasi yang } \\
\text { ditunjukkan oleh } \\
\text { signage sudah efektif } \\
\text { dan ringkas } \\
\text { memudahkan untuk } \\
\text { dibaca. Signage dibuat } \\
\text { besar serta tinggi agar } \\
\text { pengunjung mudah } \\
\text { untuk melihatnya. }\end{array}$ & $\begin{array}{l}\text { Informasi yang } \\
\text { ditunjukkan kepada } \\
\text { pengujung sudah } \\
\text { efektif, jelas dan } \\
\text { ringkas hanya masalah } \\
\text { penempatannya yang } \\
\text { tidak kontras. }\end{array}$ \\
\hline Legability & $\begin{array}{l}\text { Karakter huruf sudah } \\
\text { tepat namun spasi huruf } \\
\text { masih terlalu berdekatan } \\
\text { serta kontras huruf } \\
\text { dengan background tidak } \\
\text { sesuai. }\end{array}$ & $\begin{array}{l}\text { Karakter huruf mudah } \\
\text { dibaca serta ukuran } \\
\text { font yang sesuai tidak } \\
\text { besar ataupun kecil. }\end{array}$ & $\begin{array}{l}\text { Ukuran font terbaca } \\
\text { dengan jelas namun } \\
\text { karakter huruf yang } \\
\text { kurang terbaca. }\end{array}$ \\
\hline
\end{tabular}

Sumber: Maymun dan Swasty, 2017 
Tabel di atas membandingkan tiga proyek sejenis signage yang terdapat pada tiga area wisata. D'ranch dan Kampung Gajah dipilih sebagai pembanding karena dua area wisata tersebut sudah memiliki placemaking yang sesuai dengan identitas merknya.

Dari hasil analisis data matriks pada tabel I, ditarik kesimpulan bahwa signage yang ada saat ini kurang diperhatikan dan tidak sesuai dengan identitas visualnya. Terkadang ada pengunjung yang merasa kebingungan karena signagenya terlalu kecil dan petunjuk arah yang jarang. Peta yang ada saat ini pun hanya dibuat seadanya saja. Karena itu dibutuhkan perbaikan dan pembaruan terhadap desain identitas visual yang menarik serta signage informatif yang mudah untuk dibaca. Selain membuat signage menjadi salah satu identitas tempatnya signage dapat memperindah lingkungan di kawasan wisata Kampung Batu Malakasari. Konsep visual yang akan diimplementasikan pada desain logo dan signage didapat dari mind mapping yang dijabarkan pada tabel 2 berikut:

Tabel 2. Konsep Perancangan Identitas Visual dan Signage

\begin{tabular}{|l|l|}
\hline Konsep & \multicolumn{1}{|c|}{ Keterangan } \\
\hline Tema & $\begin{array}{l}\text { Tema yang diambil dari ciri khas Kampung Batu Malakasari } \\
\text { yaitu wisata yang edukatif. }\end{array}$ \\
\hline Bentuk & $\begin{array}{l}\text { Bentuk diambil dari ciri khas Kampung Batu Malakasari } \\
\text { yaitu alam bebatuan dan rusa totol. }\end{array}$ \\
\hline Tipografi & $\begin{array}{l}\text { Tipografi yang digunakan adalah jenis dekoratif untuk } \\
\text { logo dan sans serif untuk signagenya. }\end{array}$ \\
\hline Warna & $\begin{array}{l}\text { Warna logo yaitu warna orange untuk background, coklat } \\
\text { untuk tekstur batu serta warna rusa dan warna hijau, biru } \\
\text { sebagai warna dari nuansa alam. } \\
\text { Warna signage yaitu warna abu untuk background, hijau } \\
\text { untuk pictogram, biru untuk elemen desain dan putih } \\
\text { untuk warna font. }\end{array}$ \\
\hline Material & $\begin{array}{l}\text { Material yang digunakan pada signage menggunakan batu } \\
\text { alam, semen, kawat besi dan kayu }\end{array}$ \\
\hline
\end{tabular}




\section{Konsep Visual dan Hasil Perancangan Logo}

Dalam proses pembentukan identitas visual, dibutuhkan sebuah logo yang menjadi identitas diri sebagai tanda kepemilikan, selain itu logo juga sebagai tanda jaminan kualitas dan untuk mencegah peniruan identitas (Rustan, 2013). Logo akan dibuat sesuai dengan ciri khas dari Kampung Batu Malakasari yakni dengan ciri khasnya adalah gunung batu dan rusa totol (Axis axis) yang menjadi ikonnya.

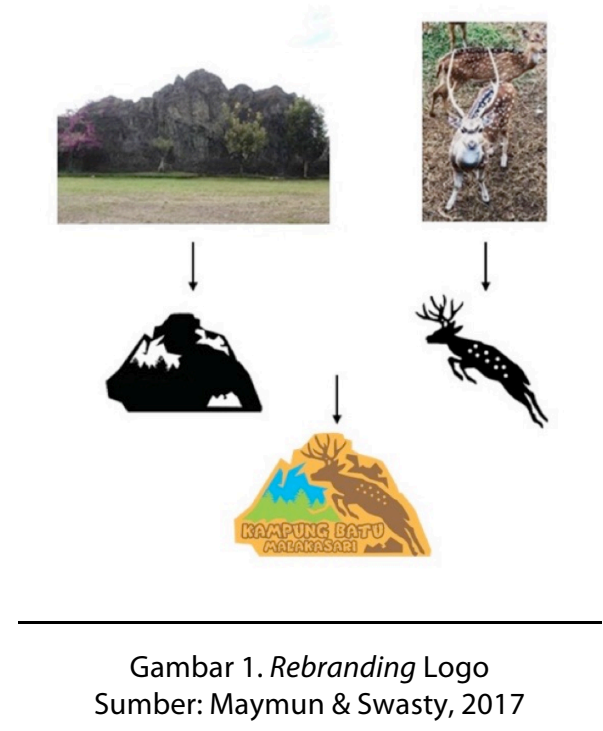

Logo pada Kampung Batu Malakasari ini menggunakan elemen grafis dari bentuk gunung batu dan rusa totol yang sedang meloncat. Rusa yang sedang meloncat sebagai sosok rusa yang aktif yakni kawasan wisata Kampung Batu Malakasari mengusung konsep wisata edukasi sehingga wahana-wahana yang ada di dalamnya harus bermain dengan aktif. Logo Kampung Batu Malakasari dibagi menjadi dua yaitu logogram dan logotype yang menjadi satu kesatuan (gambar 1).

Logo Kampung Batu ini merupakan gabungan antara logogram dan logotype yang mewakili dari identitas visual kampung wisata tersebut dari bentuk yang menyerupai gunung batu. Rusa totol yang aktif menandakan sebagai bentuk dari visual edukasi dan juga logotype yang menyerupai bentuk batu yang menyempurnakan logogram. 


\section{Konsep Visual dan Hasil Perancangan Signage}

Dalam perancangan signage akan ada tiga unsur yang akan ditampilkan yaitu pictogram (simbol dan tanda panah), tulisan untuk melengkapi pictogram, dan logo Kampung Batu Malakasari. Desain pictogram yang akan diterapkan diporoleh dari tema, mind mapping serta mooboard yaitu memiliki bentuk siku-siku seperti batu. Untuk warna diperoleh dari warna alam hijau dan biru sedangkan warna abu untuk warna latarnya diambil dari warna batu. Menurut Calori (2007), berdasarkan standarisasi signage, dapat dibagi menjadi beberapa jenis, yaitu identification sign, directional sign, operational sign, warning sign, dan interpretive sign.

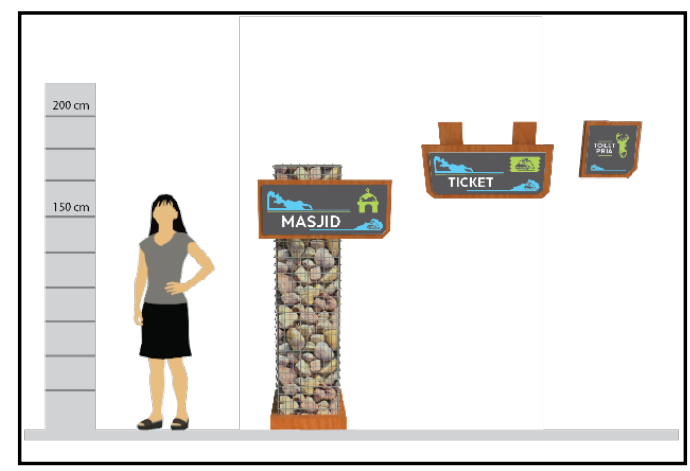

Gambar 2. Identification sign Sumber: Maymun \& Swasty, 2017

Identification sign dibagi menjadi 3 jenis yaitu wall mounted, ground mounted, dan ceiling hug. Wall mounted ini bertujuan untuk menginformasikan wahana dan fasilitas serta memiliki ukuran yang berbeda-beda, disesuaikan dengan fungsi dan penempatannya. Ground mounted ini digunakan sesuai kebutuhan lokasi dari fasilitas dan wahana yang ada. Sama halnya dengan kedua fungsi signage di atas, hanya saja bentukan dari ceiling hug ini ditempelkan pada pintu, pohon, tembok, dan sebagainya. Jadi, perbedaan dari ketiga signage di atas adalah dari jenis bentukannya.

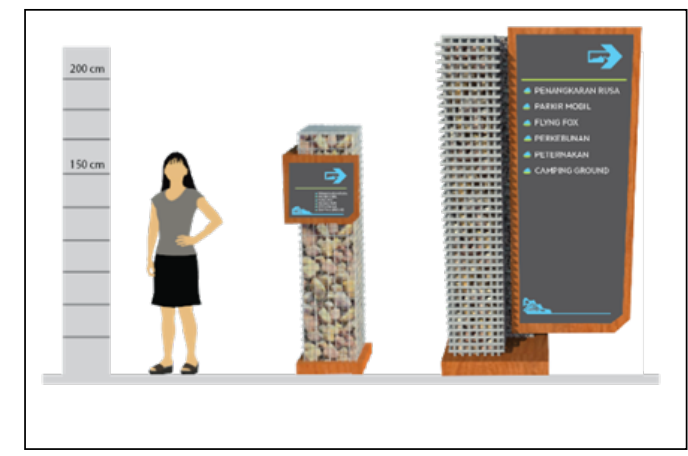

Gambar 3. Directional Sign

Sumber: Maymun \& Swasty, 2017 
Directional sign yang digunakan untuk penunjuk arah lokasi yang akan dituju pengunjung. Jenis yang digunakan untuk directional sign yaitu jenis free-standing sign karena penempatannya digunakan untuk tempat di luar ruangan (outdoor).

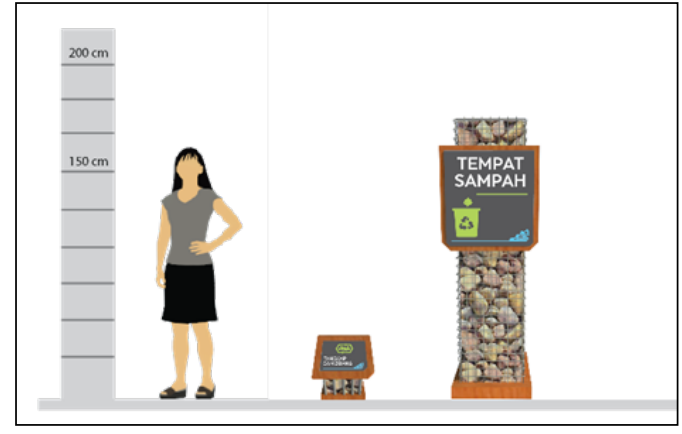

Gambar 4. Regulatory sign Sumber: Maymun \& Swasty, 2017

Signage regulatory ini sebagai tanda peringatan kepada pengunjung yang dibagi menjadi dua jenis yaitu free-standing dan ground mounted. Untuk free-standing berisi pesan seperti "dilarang membuang sampah". Sedangkan untuk ground mounted berisi pesan seperti "pancing dan lepaskan".

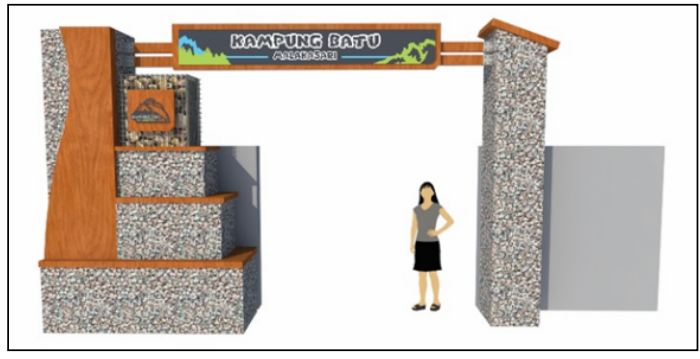

Gambar 5. Placemaking Sumber: Maymun \& Swasty, 2017

Placemaking yang dibuat berupa gapura tempat masuk menuju kawasan wisata Kampung Batu Malakasari. Material yang digunakan pada gapura ini yaitu perpaduan antara batu dan kayu. 


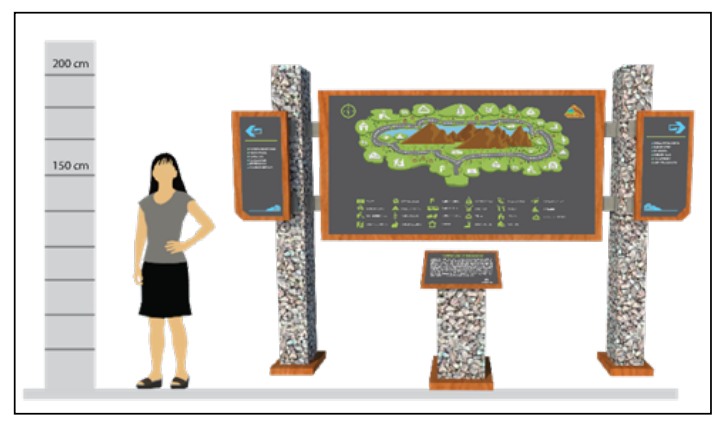

Gambar 6. Wayfinding

Sumber: Maymun \& Swasty, 2017

Wayfinding berupa peta dipadukan dengan interpretive sign dan di bagian sisi kanan dan kiri disatukan dengan directional sign.

\section{PENUTUP}

Hasil dari observasi dan analisis yang dilakukan, didapat kesimpulan bahwa dibutuhkan upaya untuk membangun identitas visual yang dapat menciptakan ciri khas kuat pada kawasan wisata dan meningkatkan awareness pada pengunjung. Oleh karena itu, pembuatan signage dirancang lebih menarik dan konsisten melalui visualisasi yang sesuai dengan identitas tempat tersebut. Hal ini bertujuan untuk menarik perhatian dan memudahkan pengunjung saat berada di kawasan wisata tersebut. Selain itu, ketepatan penempatan signage harus sesuai dengan standarisasi untuk membantu pengunjung dalam menemukan lokasi wisata.

Dalam perancangan ini masih terdapat beberapa kekurangan. Perancangan hanya fokus pada identitas visual yang diterapkan pada signage dan wayfinding, sedangkan objek pada perancangan ini merupakan sebuah wisata edukasi. Untuk penelitian selanjutnya, studi mengenai kampanye pemasaran untuk membangun destination branding menarik untuk dilakukan. Selain itu, studi mengenai kampanye sosial tentang pentingnya wisata edukasi dapat dilakukan.

\section{DAFTAR PUSTAKA}

Anggraeni, L. \& Kirana, N. (2014). Desain Komunikasi Visual, Dasar - dasar Panduan untuk Pemula. Bandung: Nuansa Cendekia.

Burkart, A.J. and Medik, S. (1988). Tourism: Past Present and Future. London : Heinenman Calori, C. (2007). Signage and Wayfinding Design. s.l.:John Wiley \& Sons. 
Christianna, Aniendya. (2016). Desain Signage Sebagai Solusi Pencemaran Visual. Jurnal Desain Komunikasi Visual. repository : Universitas Kristen Petra.

Damanik, J. dan Weber, H. F. (2006). Perencanaan Ekowisata - dari Teori ke Aplikasi. Yogyakarta: Andi Offset.

Heskett, Jhon. (2014). Desain Industri. Jakarta: CV Rajawali.

Riverwalk. Wayfinding and Accessibility in the San Antonio Riverwalk, Volume Design Education: Explorations and Prospects for a Better Built Environment.

Pitana, I Gede dan Putu Gede Gayatri. 2005. Sosiologi Pariwisata. Yogyakarta. Andi.

Rustan, S. (2013). Mendesain Logo. Jakarta: Gramedia Pustaka Utama.

Shimp, Terrence, A. (2003). Komunikasi Pemasaran Terpadu. Jakarta: Erlangga

Rendra, Suroso, 2004. Sosiologi Pariwisata. Yogyakarta: Andi

Ruslan, S., 2008. LAYOUT dasar dan penerapannya. Jakarta: PT Gramedia Pustaka Utama. 